\title{
A Rare Presentation of Pulsating Thoracoabdominal Mass
}

\author{
Dr. Malay Jhancy ${ }^{1}$, Ammar Al Homsi ${ }^{2 *}$, Mohammad Al Homsi ${ }^{2}$
}

\author{
${ }^{1}$ Associate Professor, Department of Pediatrics, RAK Medical and Health Sciences University, UAE, Former Assistant Professor of Pediatrics, \\ Rangaraya Medical College, Kakinada, India \\ ${ }^{2}$ RAK College of Medical Sciences, RAK Medical and Health Sciences University, UAE
}

DOI: $10.36347 /$ simcr.2020.v08i02.045

| Received: 17.02.2020 | Accepted: 24.02.2020 | Published: 29.02.2020

*Corresponding author: Ammar Al Homsi

Abstract

Case Report

Ectopia Cordis is a partial or total protrusion of the heart outside the thoracic cavity. It accounts for $0.1 \%$ of congenital heart diseases [1]. This rare malformation can be a part of a syndrome called the Pentalogy of Cantrell, which is a constellation of five congenital defects. In its complete form, it presents with a defect of the heart, pericardium, diaphragm, sternum and abdominal wall [2]. These defects pose a challenge for surgeons, and early identification with strategic planning for management is essential for the survival of the patient. The author reports a case of ectopia cordis associated with a probable diagnosis of Pentalogy of Cantrell, in a neonate presenting with pulsating thoracoabdominal mass, sternal, and abdominal wall defect.

Keywords: Ectopia Cordis, Pentology of Cantrell, Diaphragmatic hernia

Copyright @ 2020: This is an open-access article distributed under the terms of the Creative Commons Attribution license which permits unrestricted use, distribution, and reproduction in any medium for non-commercial use (NonCommercial, or CC-BY-NC) provided the original author and source are credited.

\section{INTRODUCTION}

Pentalogy of Cantrell is a rare cause of thoracoabdominal mass, presenting with five congenital defects. Its rare and lethal condition, where prompt management is essential for the patient survival. We present a case of male baby, born with pulsating mass in the thoracoabdominal region.

\section{CASE Report}

A male baby was born at term gestation by normal vaginal delivery with a weight of $3.5 \mathrm{kgs}$, to 22 year-old primigravida mother in a government hospital, in Kakinada, India. Apgar score of 7 at 1 minute and 8 at 5 minutes was noted with oxygen saturation of $80 \%$. He was cyanosed with respiration more than 60 breaths per minute, kept on free-flow oxygen, and heart rate of 150 beats per minute.

$\mathrm{He}$ is the first-born to non-consanguineous parents, antenatal checkup was done at $3^{\text {rd }}$ month, and $8^{\text {th }}$ month. Anomaly scan wasn't done due to the financial constraints of the parents. No history of congenital conditions in the family and no history of maternal infection, drug exposure or radiation exposure during pregnancy.

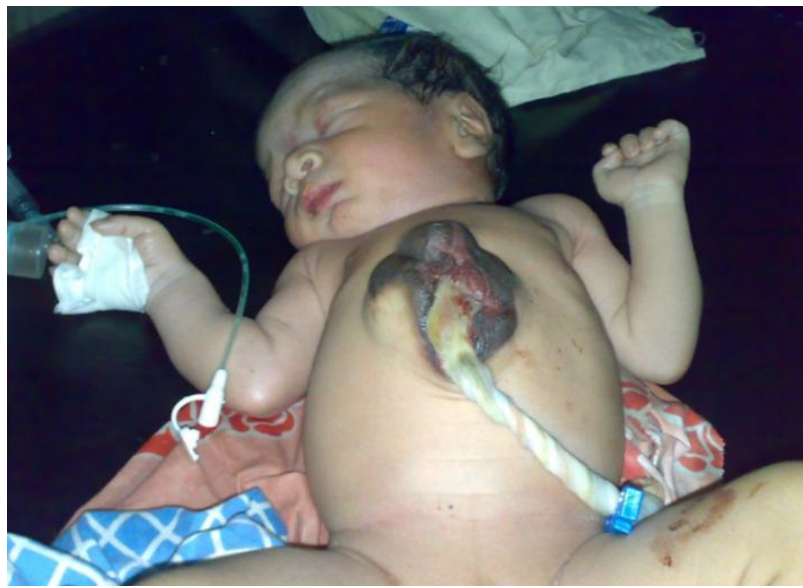

Fig-1: Pulsating Thoracoabdominal mass with displacement of the umbilicus

On examination, patient had signs of respiratory distress with chest retractions. There was a large pulsating heart covered with a thin layer of pericardium at the mid-thoracoabdominal area, with distortion of the umbilicus (Figure-1). The umbilical cord was displaced towards the upper abdomen and a small omphalocele was noted. Abdomen was scaphoid and a lower sternal defect was felt with skin covering it. On auscultation, decreased breath sounds on the left side, and gurgling bowel sounds were heard in the left chest. Parents were counseled about the complexity of the disease and the need for investigations and shift to a higher center for specialty care. As parents did not 
consent for further treatment, no investigations were done, the child expired within 2 hours of birth due to heart failure.

Patient was diagnosed clinically as having Ectopia Cordis with the possibility of Pentalogy of Cantrell Class 2 based on the clinical findings of omphalocele, abdominal and sternal defects, with a possibility of diaphragmatic hernia suspected because of the presence of scaphoid abdomen and ausculted bowel sounds in the left chest. The autopsy wasn't done because of the parent's refusal.

\section{DISCUSSION}

The pentalogy of Cantrell or Cantrell's syndrome was first described by James $\mathrm{R}$ Cantrell in 1958. It is a rare and lethal condition presenting with five cardinal features: a midline supraumbilical abdominal wall defect, a defect of the lower sternum, a deficiency of the anterior diaphragm, a defect in the diaphragmatic pericardium, and congenital intracardiac defects. Ectopia Cordia, defined as the partial or complete displacement of the heart is a typical feature seen in most of the cases. The proposed pathogenesis involves a defect in the differentiation of intraembryonic mesoderm that takes place between 14 and 18 days after conception [3].

Pentalogy of Cantrell is a rare malformation, with an incidence that varies from 5.5 to 7.9 per million live births [4], affecting both genders but more predominance to male, the male to female ratio is $2: 1.2$ $[3,8]$.

This syndrome has variable expressions. The complete form has the following defects [3]:

- Supraumbilical abdominal wall defect with omphalocele;

- Lower sternal defect;

- Ectopia cordis;

- Anterior diaphragmatic defect;

- Diaphragmatic pericardial defect and intracardiac abnormalities

Majority of the cases are sporadic, although siblings with Pentalogy of Cantrell were reported, suggesting probability of familial inheritance. Although multiple causes of the Pentalogy of Cantrell are accompanied by chromosomal abnormalities such as Trisomy 18, 21 or Turner's syndrome, no discreet genetic mutation has been considered responsible for the Pentalogy of Cantrell [5].

The degree of severity varies and was classified by Toyama in 1972 based on a review of 61 cases of Pentalogy of Cantrell. Three classes were based on the spectrum of expression [6]:
Class 1-a complete form of the syndrome, having all five defects (definitive diagnosis);

Class 2-four defects including ventral wall and intracardiac abnormalities (probable diagnosis);

Class 3-incomplete form having various combinations of defects but with sternal abnormality (incomplete expression).

Analysis of literature for malformations of 153 patients with complete and incomplete Cantrell's Syndrome showed that [7]:

\begin{tabular}{|l|l|}
\hline & $\begin{array}{l}\text { Percent of } \\
\text { all 153 cases }\end{array}$ \\
\hline Heart defects & $83 \%$ \\
\hline Abdominal wall defects & $74 \%$ \\
\hline Sternal malformation & $59 \%$ \\
\hline Diaphragmatic defects & $57 \%$ \\
\hline Pericardial defects & $42 \%$ \\
\hline Craniofacial and limb anomalies & $28 \%$ \\
\hline
\end{tabular}

The occurrence of congenital intracardiac anomalies is a constant element of this syndrome [3]. Ventricular septal defect was the most common heart malformation, found in $60 \%$ of all cases. The pericardium was absent in $31 \%$ of all cases. The most frequent abdominal wall defect was omphalocele, present in $47 \%$ of all cases [7].

With prenatal ultrasonography, Pentalogy of Cantrell can, for the most part, be diagnosed as early as 10 weeks of pregnancy. It has been proposed that magnetic resonance imaging and prenatal fetal echocardiography provide an optimal assessment of fetuses with Pentalogy of Cantrell. Utilizing 2D ultrasound in the first trimester, and the adjunctive utilization of the 3D ultrasound may assist to enhance the visualization of the fetal anomalies in various orthogonal planes, even in unfavorable fetal positions $[8,9]$.

Management of patients with the Pentalogy of Cantrell requires the coordination of multiple specialties, this includes neonatal resuscitation, temporary coverage of the defects and palliative or corrective intracardiac repair along with thoracoabdominal reconstruction. Both multi-stage and single-stage surgical repair has been described and performed in complete and incomplete Pentalogy of Cantrell. Multi-stage surgical management is preferable. The benefits of the staged repair are: minimisation of the compression of the heart and the great vessels, and to allow the thoracic cavity to expand gradually. Because of the increased risk of mortality with surgical intervention, stable neonates may benefit from initial conservative management, whereas cirtically ill neonates require full life support and timely surgical intervention managed by multidisciplinary team in the neonatal intensive care unit. Corrective operations for the Pentalogy of Cantrell poses a 
challenge because of the complexity of the anomalies and the associated high mortality. A comprehensive evaluation of the patient is required before the decision of operative repair. Best treatment strategy should be well-planned and uniquely individualized to attain both structural integrity and hemodynamic stability $[5,10]$.

The survival rate for the Pentalogy of Cantrell remains as low as $37 \%$ [7]. The prognosis depends primarily on the type and the severity of associated malformations and intra-cardiac anomalies, but also on the location of the ectopic heart. The prognosis in cases of ectopia cordis is worse, in contrast to thoracoabdominal ectopia [11]. Few patients with Pentalogy of Cantrell and significant ectopia cordis survive surgical repair, and the main causes of death include tachyarrhythmias, bradycardia, hypotension, rupture of the diverticulum, and heart failure. The survival rate has improved to $61 \%$ with considerable advances in pediatric surgery and neonatal intensive care $[5,12,13]$.

\section{CONCLUSION}

The Pentalogy of Cantrell is a rare congenital abnormality with very few cases reported in the literature, but it should be considered in patients presenting with Ectopia Cordis. Our case clearly had clinical features suggestive of Pentalogy of Cantrell even though it wasn't proved by investigations, due to financial constraints. This case report is worth for publication as a contribution to the existing literature.

\section{ACKNOWLEDGEMENTS}

We thank the parents of the patient described for allowing us to share their child's details.

\section{REFERENCES}

1. Sadłecki P, Krekora M, Krasomski G, Walentowicz-Sadłecka M, Grabiec M, Moll J, Respondek-Liberska M. Prenatally evolving ectopia cordis with successful surgical treatment. Fetal diagnosis and therapy. 2011;30(1):70-2.
2. Anderson Roberth. Abnormal Positions and Relationships of the Heart. In Paediatric cardiologyv 3rd edition, Philadelphia: Churchill Livingstone Elsevier; 2009.

3. Cantrell JR, Haller JA, Ravitch MM. A syndrome of congenital defects involving the abdominal wall, sternum, diaphragm, pericardium, and heart. Surg Gynecol Obstet. 1958;107(5):602-14.

4. Carmi R, Boughman JA. Pentalogy of Cantrell and associated midline anomalies: A possible ventral midline developmental field. American Journal of Medical Genetics. 1992;42(1):90-5.

5. Williams AP, Marayati R, Beierle EA. Pentalogy of Cantrell. Seminars in Pediatric Surgery. 2019;28(2):106-10.

6. Toyama WM. Combined congenital defects of the anterior abdominal wall, sternum, diaphragm, pericardium, and heart: a case report and review of the syndrome. Pediatrics. 1972;50(5):778-92.

7. Vazquez-Jimenez JF, Muehler EG, Daebritz S. Cantrell's Syndrome: A Challenge to the Surgeon. The Annals of Thoracic Surgery. 1998;65(4):117885.

8. Kumar B, Sharma C, Sinha D. Ectopia cordis associated with Cantrells pentalogy. Annals of Thoracic Medicine. 2008;3(4):152-3.

9. Rodgers EB, Monteagudo A, Santos R. Diagnosis of Pentalogy of Cantrell Using 2- and 3Dimensional Sonography. Journal of Ultrasound in Medicine. 2010;29(12):1825-8.

10. Abdallah HI, Marks LA, Balsara RK. Staged repair of pentalogy of Cantrell with tetralogy of Fallot. Ann Thorac Surg. 1993;56(4):979-80.

11. Skandalakis JE, Gray SW. The anterior body wall. In Embryology for surgeons, 2nd ed, Baltimore, 1994. 552-9.

12. Morales J, Patel SG, Duff JA. Ectopia cordis and other midline defects. The Annals of Thoracic Surgery. 2000;70(1):111-4.

13. Diaz JH. Perioperative Management of Neonatal Ectopia Cordis. Anesthesia \& Analgesia. 1992;75(5):833-7. 